\title{
ELAZIĞ İLI İÇİN GÜNEŞ ISISI KAZANÇ FAKTÖRÜNÜN YÖNLERE GÖRE DEĞİŞİMİNİN DENEYSEL OLARAK ÍNCELENMESİ
}

\author{
Betül BEKTAŞ EKİCi ${ }^{1}$, U. Teoman AKSOY ${ }^{2}$ \\ ${ }^{1}$ Frrat Üniversitesi, Mimarlık Fakültesi, Mimarlık Bölümü, 23119, Elazı̆̆ \\ ${ }^{2}$ Fırat Üniversitesi, Teknoloji Fakültesi, İnşaat Mühendisliği Bölümü, 23119, Elazığ \\ $\underline{\text { bbektas@firat.edu.tr, taksoy@firat.edu.tr }}$
}

(Geliş/Received: 24.12.2013; Kabul/Accepted: 05.11.2015)

\begin{abstract}
ÖZET
Bu çalışmada tek bölmeden oluşan bir bina prototipinin yatay ve dört ana yöne bakan düşey yüzeyleri üzerine gelen güneş ışınımı piranometrelerle ölçülmüş ve bir veri kaydedicisiyle kayıt altına alınmıştır. Ölçümler sonucu elde edilen güneş ışınımı verilerinden sayısal bağıntılar yardımıyla güneş ışınımının doğrudan, yayılı ve yansıyan bileşenleri hesaplanmıştır. Ölçümleri yapıldığı 27 Temmuz 2010- 4 Temmuz 2011 tarihleri arasındaki 343 güne ait saatlik Güneş Isısı Kazanç Faktörü (GIKF) değerleri hesaplanarak aylık ortalama saatlik GIKF değerleri elde edilmiştir. Hesaplamalar MATLAB ortamında yazılan bir bilgisayar programı ile gerçekleştirilmiştir. Sonuç olarak ASHRAE'nin $40^{\circ}$ kuzey enlemi için vermiş olduğu değerlerin ölçüm yapılan dönem için hesaplanan GIKF değerlerinden farklı yönler için değişmekle birlikte \% 2,3 ile yaklaşı \% 90 civarında yüksek olduğu durumlara rastlanmıştır.
\end{abstract}

Anahtar Kelimeler: Güneş 1şınımı, güneş 1sısı kazanç faktörü, binalarda enerji etkinlik

\section{EXPERIMENTAL INVESTIGATION OF THE VARIATION OF SOLAR HEAT GAIN FACTORS DUE TO ORIENTATIONS FOR ELAZIĞ PROVINCE}

\begin{abstract}
Solar radiations on the horizontal, four main vertical surfaces of a building prototype consisting of a single pane building prototype, are measured with pyranometers and recorded with a datalogger. Direct, diffuse and reflected components of the measured solar radiations were determined by using numerical correlations. The monthly average hourly Solar Heat Gain Factors (SHGF) were obtained by calculating SHGF's belonging to 343 days of the measurement period between 27 July 2010- 4 July 2011. The calculations were carried out with a computer program written in MATLAB. As a result when compared with the calculated SHGF's for the measurement period ASHRAE's $40^{\circ}$ values were found to be high with between $2.3 \%$ and nearly $90 \%$ for different directions.
\end{abstract}

Keywords: Solar radiation, solar heat gain factor, energy efficiency in buildings

\section{GÍRIŞ (INTRODUCTION)}

Dünyanın pek çok ülkesinde olduğu gibi Türkiye'de de binalarda, özellikle konutlarda tüketilen enerji miktarı toplam enerji tüketimi içerisinde önemli bir yere sahiptir [1-3]. Aktif güneş enerjisi sistemleri ve bina yönlenmesi, seçilecek yapı malzemeleri, pencereler gibi pasif güneş tasarım parametreleriyle birleştirildiğinde, fosil yakıt tüketimine daha az bağımlı, konforlu mekânlar oluşturmak mümkündür.
Aksi halde iç ortam konfor koşullarının tamamı veya önemli bir kısmı 1sıtma-soğutma, aydınlatma ve havalandırma sistemleri tarafindan karşılanmaktadır [4]. $\mathrm{Bu}$ durum tüketilecek fazla enerji ile birlikte; küresel ısınmaya, fosil kaynakların tükenmesine, hava kirliliğine, çevresel hasarlara, kullanıcılar ve ülke ekonomisi açısından ağır maliyetlere neden olmaktadır. Binalarda kullanılan enerji miktarını belirleyen değişkenlerin başında bölgesel iklim koşulları gelmektedir. $\mathrm{Bu}$ nedenle farklı iklim 
bölgelerinin geleneksel yapı üretim teknikleri birbirinden farklı özellikler göstermektedir. Ancak çağdaş yapılaşma anlayışı, yeni akım ve malzemelerin de etkisiyle, farklı iklim bölgeleri için aynı tasarım ve yapım yöntemlerini öngördüğünden, yapılardan beklenen konfor koşullarının sağlanması ikinci planda kalmıştır. Güneş ışınımı, diğer iklimsel değişkenlerin yanı sıra, yapıların doğal aydınlatma, pasif ısıtma ve iklimlendirme sistemleri olarak işlev görmelerinde kullanılan bir tür enerjiyi oluşturur. Bina diş yüzey elemanları üzerlerine düşen güneş 1şınımından doğrudan etkilenmekte ve bu durum iç ortam konfor koşullarına yansımaktadır. İç ve dış yüzeylerinden güneş 1şınımı ve sıcaklık ölçümleri gerçekleştirilen bina prototipinin batı yönüne bakan yüzeyi için verilen Şekil 1 incelendiğinde yüzey sıcaklıklarının güneş 1şınımı şiddetine bağlı olarak doğrudan değiştiği net olarak görülmektedir. Bina diş yüzeyleri üzerine gelen güneş 1şınımının en yüksek olduğu saatlerde yüzey sıcaklık değerleri de en yüksek değere ulaşmaktadır. Yapı yüzeylerindeki güneş 1şınımının enerji potansiyeli; bölgeye, yapıların kullanıldığı döneme, yapı yüzeylerinin yönü ve eğimine göre değişkenlik göstermektedir. $\mathrm{Bu}$ nedenle bölgesel güneş enerjisi potansiyelinin bilinmesi gerekmektedir. Isıtmanın istendiği kış aylarında, az güneş ışınımı ve az güneş 1sısı kazancı daha fazla 1sıtma ihtiyacı ve yakıt tüketimi anlamına gelmektedir. Bunun tam tersi durum sıcak yaz aylarındaki fazla güneş 1şınımı ve fazla güneş 1sısı kazanc1, büyük soğutma ekipmanı ihtiyacı ve elektrik sarfiyatına sebep olmaktadır.

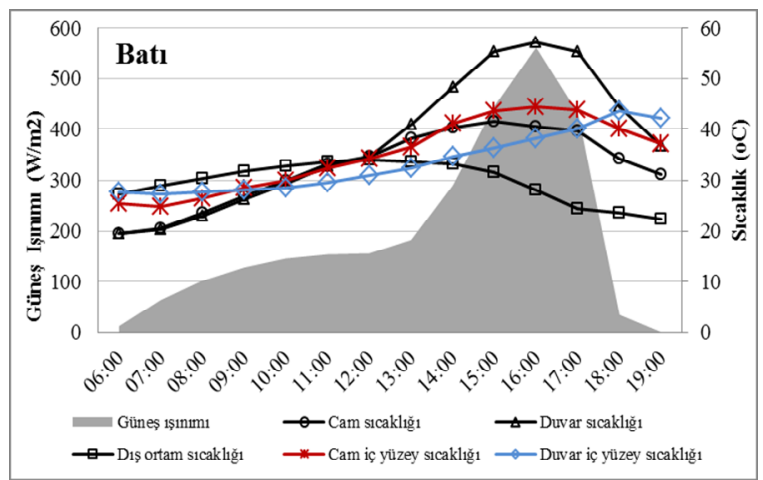

Şekil 1. Farklı cepheler için yüzey sıcaklıklarının güneş 1şınımına bağlı olarak değişimi [5] (Variation of surface temperatures due to solar radiation for different facades)

Bina içerisine giren güneş 1SıSı, GIKF parametresiyle tanımlanmaktadır. Bu parametre binaların isitma ve soğutma yükü tayininde camlı yüzeylerden (pencerelerden) olan güneş 1S1S1 kazancinın hesaplanmasında kullanılmaktadır. GIKF, Amerika Isıtma, Soğutma ve İklimlendirme Mühendisleri Birliği (ASHRAE) hesaplama yöntemine göre 33,38 mm kalınlığında, 0,86 geçirme, 0,08 yansıtma ve 0,06 yutma oranlarına sahip referans cam için güneş ışınımından elde edilen 1 sı kazancı $\left(\mathrm{W} / \mathrm{m}^{2}\right)$ değerini ifade etmektedir [6]. Her ayın 21. günü için referans camın yukarıda verilen solar-optik özellikleri kullanılarak hesaplanmış olan GIKF değerleri 8'er derece arayla $0^{\circ}$ 'den $64^{\circ}$ 'ye kadar farklı enlemler için hazırlanmış olan tablolarda yatay ve düşey yüzeyler için verilmektedir. GIKF ile ilgili olarak literatürde pek çok çalışma mevcuttur. Li ve Lam [7], subtropikal iklim bölgelerinde, gökyüzü berraklık indeksi ve güneş geometrisini temel alan enerji etkin bina tasarımında kullanılabilecek yaklaşık GIKF değerlerini tanımlamışlardır. Ölçülen ışınım verilerini kullanarak hesapladıkları GIKF önemli seviye değerlerini ASHRAE açık gökyüzü modeline ait değerlerle karşılaştırmışlardır. Marinoski vd. [8], pencerelerden güneş 1S1S1 kazancının ölçülebilmesi amacıyla bir sistem geliştirerek oda içerisine giren 1sıyı ve güneş faktörünü tanımlamışlardır. Li ve Lam [9], Hong Kong Üniversitesi gözlemevinde uzun yıllar boyunca ölçülen yatay ve düşey yüzeylere ait güneş 1şınımı verilerini kullanarak saatlik GIKF değerlerinin hesaplanacağı bir yöntemi sunmuşlardır. Bhandari ve Bansal [10] Hindistan'in tipik iklimsel koşullarını göz önünde bulundurarak, pasif 1sıtma elemanları ve binaya ait diğer bileşenler için net 1sı kazancının hesaplanmasında GIKF parametresini kullanmışlardır. Pasif ısıtma hesaplarında kullanılması amacıyla GIKF ve ilgili 1sı kaybı katsayılarına ait kesin analitik ifadeleri elde etmişlerdir. Li ve Lam [11], farklı güneş 1şınımı tahmin yöntemlerini birbirleri ile kıyaslamış, gerçek ölçümler ve tahmin yöntemlerinden elde ettikleri güneş 1şınımı verilerini kullanarak hesapladıkları GIKF değerlerini, ASHRAE açık gökyüzü modeli ile karşılaştırmışlardır. Hernandez vd. [12], hazırlamış oldukları deney düzeneğinin duvar ve çatılarında geçici rejimde gerçekleşen 1sı transferinin modellenmesi amacıyla yaptıkları çalışmalarında, bina yüzeyi üzerine gelen toplam güneş 1şınımını belirlerken GIKF parametresinden faydalanmışlardır. Hamdy ve Fikry [13], güneş bacalarının doğal havalandırılması ile ilgili yürüttükleri çalışmanın hesaplamalarında GIKF'den faydalanmışlardır. Levinson vd. [14], çatı ve kaldırım gibi ortak yüzeylerin güneş 1sısı kazancını tahmin edebilmek için basit bir sistem önermişlerdir. Sistemin spektral seçici yüzeylerin 1sı kazançlarını yaygın olarak kullanılan yöntemlerden daha doğru tahmin edilebileceğini öne sürmüşlerdir. Pereira ve Sharples [15], uzun ve kısa dalga ışınıma duyarlılığı olan bir radyometre yardımıyla bir pencere sistemini deneysel olarak inceleyerek, güneş 1sısı kazanç ve gölgeleme katsayıları tahmininde kullanılabilecek bir yöntem geliştirmişlerdir. Pal vd. [16], güneş 1şınımı etkisi altında pencere sisteminin toplam 1s1 iletim katsayısı ve güneş 1sısı kazanç miktarını bir simülasyon programı ile tahmin ettikleri çalışmada cam yüzeyi üzerinden deneysel olarak elde ettikleri güneş ışınımı ve sıcaklık verilerini kullanmışlardır. Li vd. [17] Hong Kong'da bir ofis binasının camlarının normal ve solar film kaplı iki ayrı durumu için, aydınlatma ve soğutma amaçlı kullanılan enerji miktarını GIKF parametresine bağlı olarak 
değerlendirmişlerdir. Sonuç olarak, pencerelerde güneş filmi kullanımı ile aydınlatmada günlük tüketimde $\% \quad 16,8$ ve $28,9 \quad \mathrm{kWh} /$ gün, soğutma yükünde de \% 37 ve $62 \mathrm{kWh} /$ gün düșüş olduğunu ifade etmişlerdir. $\mathrm{Bu}$ çalışmada $38,4^{\circ}$ kuzey enleminde dünya üzerinde sayılı olarak gerçekleştirilen düşey yüzeyler üzerinden güneş ışınımı ölçümü yapılmıştır. Elde edilen bu verilerden faydalanarak Elazığ ili ve civarı için saatlik güneş 1şınımı, rüzgar hızı ve yönü gibi iklimsel değişkenlerin kullanılmasıyla elde edilen bir parametre olan ve bina enerji performans değerlendirmesinde kullanılan saatlik GIKF değerleri hesaplanmıştır. ASHRAE'nin bölge için vermiş olduğu GIKF değerlerinin uygunluğu tartışılmıştır.

\section{GÜNEŞ IŞINIMI ÖLÇÜM DÜZENEĞİ (SOLAR RADIATION MEASUREMENT SETUP)}

Yatay ve düşey yüzeyleri üzerine gelen güneş 1şınımı şiddetinin ölçüleceği bina prototipinin inşası öncesinde Fırat Üniversitesi yerleşkesi içerisinde prototip bina üzerine çevredeki ağaç ve yapıların gölgesinin düşmeyeceği bir yer seçimi yapılmıştır. Güneş 1şınım şiddetini ölçmek için ApoGee marka silikon piranometreler kullanılmıştır. Bina prototipinin dört adet düşey ve bir adet yatay yüzeyi üzerinden güneş 1şınımı ölçümü yapan piranometreler, IOtech LogBook/360 model bir veri kaydedicisine bağlanmıştır. Anlık güneş 1şınımı değerlerinin RS-232 kablosu ile bilgisayar ortamına aktarıldığı ölçüm sisteminin şematik görünümü Şekil 2'de verilmiştir.

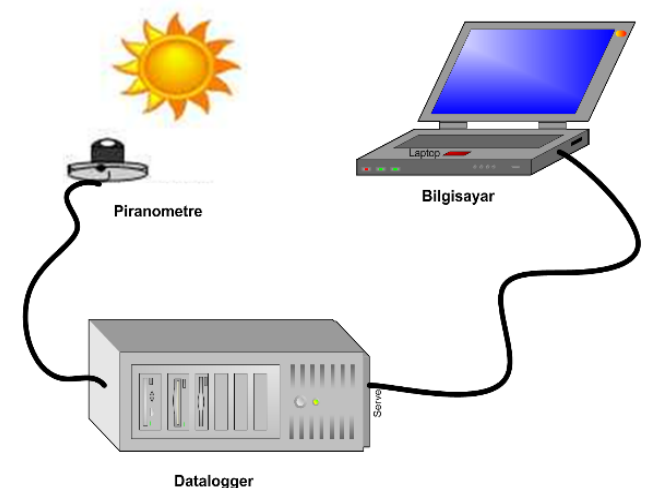

Şekil 2. Güneş 1şınımı ölçüm düzeneğinin şematik görünümü (Schematic view of the solar radiation measurement setup)

Üzerinden güneş 1şınımı ölçümlerinin gerçekleştirildiği tek bölmeden oluşan bina prototipinin iç ve diş görünüşü Şekil 3'de verilmiştir. Güneş 1şınımı şiddeti değerleri her 50 saniyede bir 1 GB belleğe sahip harici hafiza kartı ile kayıt altına alınmıștır. Ölçüm yapılacak kanallar, örnekleme ve ölçüm aralığı değerlerinin belirlenmesi ve verilerin bilgisayar ortamına aktarılması için Logview paket programı kullanılmıştır.

\subsection{Güneş Işınımı Verilerinin Değerlendirilmesi (Evaluation of Solar Radiation Data)}

Hesaplama yönteminin değerlendirilmesi amacıyla rastgele bir gün (24 Ekim 2010) için ölçülen ve aynı güne ait iklimsel veriler ile hesaplanan güneş ışınımı değerleri karşılaştırılmıştır. Hesaplanan ve ölçülen güneş 1şınımı değerlerine ait karşılaştırmanın verildiği Şekil 4 incelendiğinde doğu ve batı yönündeki farklılıkların dışında diğer yönler için oldukça yakın değerler elde edilmiştir. Ölçüm yapılan bölgenin yakınında bulunan diğer yapılara ait camlı yüzeyler (doğu yönünde) ve yüksek tepeler (batı yönünde)sırasıyla yansımalar ve engellemeler nedeniyle hesaplanan değerlerden farklı sonuçların elde edilmesine yol açmıştır. Ancak bu iki yön ve belirli saatler dışında hesaplamalarla neredeyse tamamen örtüşen sonuçlar elde edilmiştir.

$\mathrm{Bu}$ çalışmada ölçülen ve hesaplanan güneş 1şınımı şiddetleri arasındaki ilişki belirlilik katsayısı (R2) katsayısından faydalanarak açıklanmıştır. Buna göre hesaplanan ve ölçülen güneş 1şınımı değerlerinin birbirine yatay düzlem için $\% 96,17$, güney için $\%$ 88,05 , kuzey için \% 88,42, doğu için \% 94,81 ve bat1 yönü için de \% 87,11 oranlarında yakınsadığı tespit edilmiştir [5].

\section{GÜNEŞ IŞINIMI BILEŞENLERININ TESPİT EDILMESI (DETERMINATION OF SOLAR RADIATION COMPONENTS)}

\subsection{Yatay Düzlem İçin Güneş Işınımı Bileșenlerinin Hesaplanması (Calculation of Solar} Radiation Components for Horizontal Surfaces)

Çalışmada yatay ve düşey yüzeyler üzerine gelen anlık tüm güneş 1şınımı değerleri piranometreler ile kayıt altına alınmıştır. Yatay düzlem üzerine gelen güneş ışınımının doğrudan ve yayılı bileșeninin tespit edilebilmesi için literatürde genellikle berraklık indeksinden $\left(\mathrm{K}_{\mathrm{t}}\right)$ faydalanılır [18-20]. Berraklık indeksi $Q$ yatay birim düzleme gelen günlük tüm güneş 1şınımı, $Q_{0}$ atmosfer dişında yatay birim düzleme gelen güneş 1şınımı, t güneşlenme süresi ve $t_{\mathrm{g}}$ gün uzunluğu olmak üzere aşağıda verilen Eşitlik (1) ile elde edilmektedir [21]. Eşitlikte yer alan a ve b değerlerinin elde edileceği bağıntılar ise Eşitlik (2) ve (3)’te verildiği gibidir.

$$
\begin{aligned}
& \mathrm{K}_{\mathrm{t}}=\frac{\mathrm{Q}}{\mathrm{Q}_{\mathrm{o}}}=\mathrm{a}+\mathrm{b} \frac{\mathrm{t}}{\mathrm{t}_{\mathrm{g}}} \\
& a=0,103+0,000017 z+0,198 \cos (\phi-\delta) \\
& b=0,533-0,165 \cos (\phi-\delta)
\end{aligned}
$$



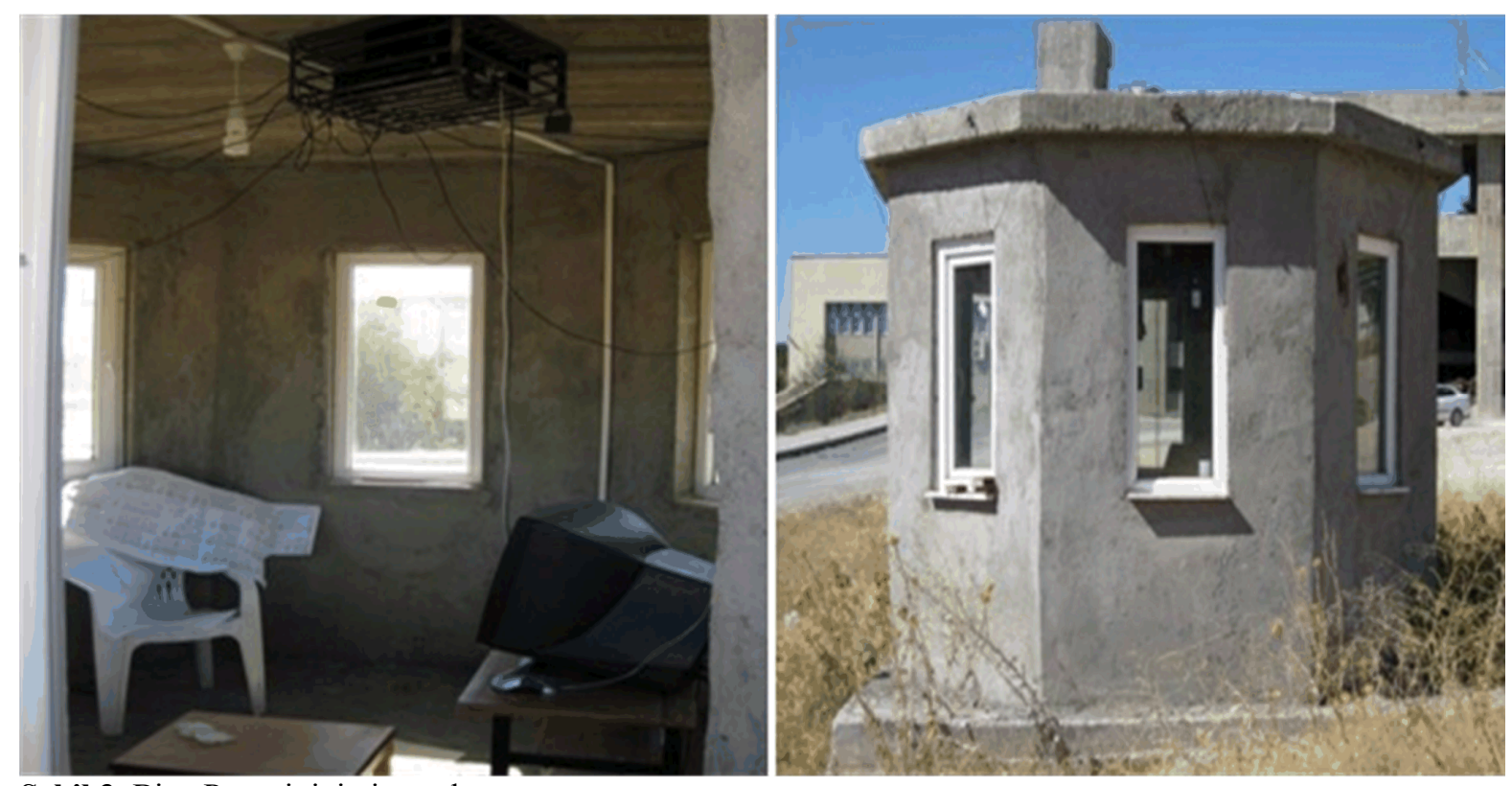

Şekil 3. Bina Prototipinin iç ve dış görünüşü (Interior and exterior views of the building prototype)
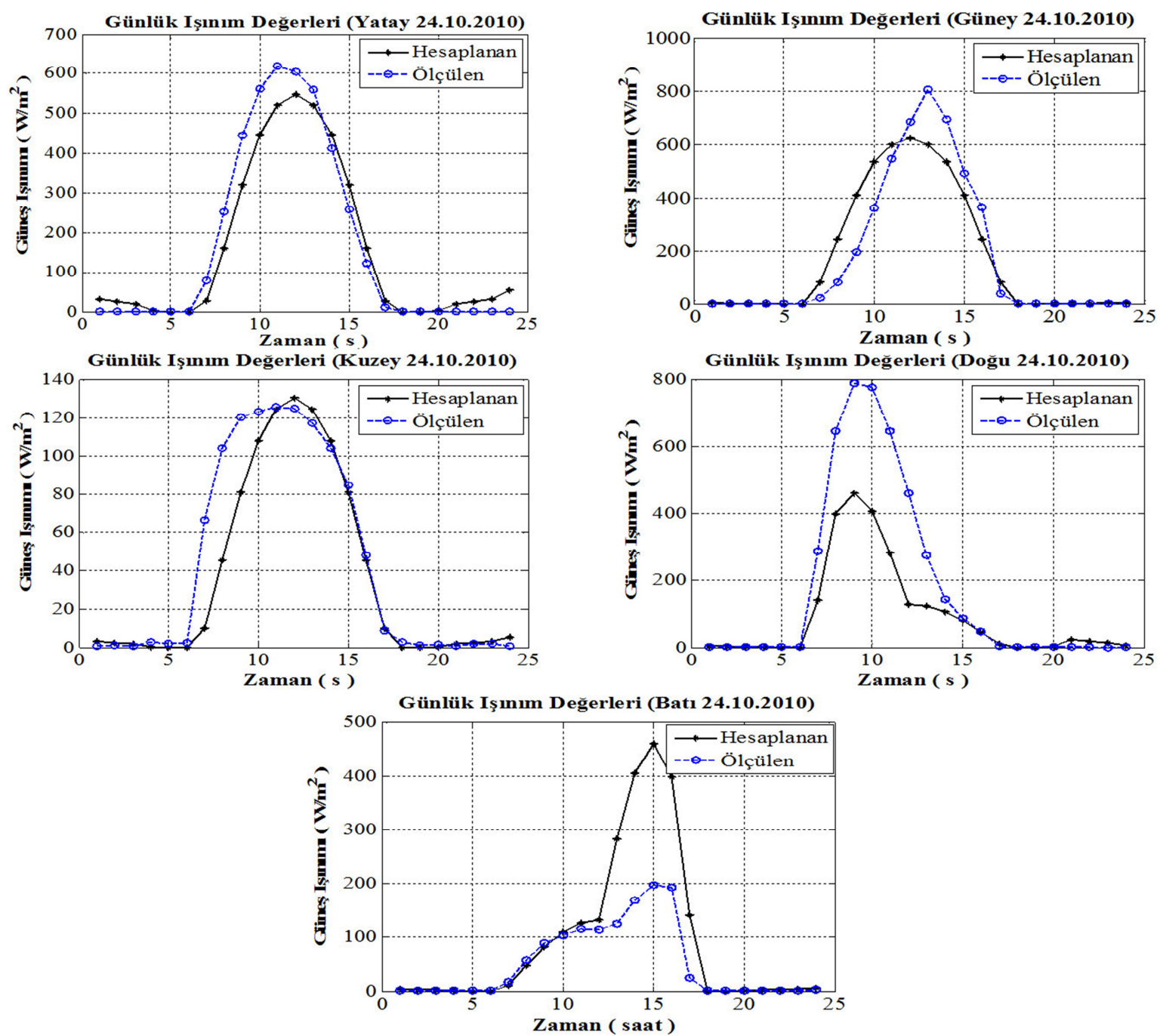

Şekil 4. Farklı yönler için ölçülen ve hesaplanan güneş ışınımı değerlerinin karşılaştırılması (Comparison of the measured and calculated solar radiations of different directions) 
Berraklık indeksinden faydalanarak yayılı ışınımın günlük tüm güneş 1şınımına oranı $\left(\mathrm{K}_{\mathrm{y}}=\mathrm{Q}_{\mathrm{y}} / \mathrm{Q}\right)$ Klein tarafindan verilen aşağıdaki polinom ile hesaplanmaktadır [22].

$$
K_{y}=1,390-4,027 K_{t}+5,531 K_{t}^{2}-3,108 K_{t}^{3}
$$

Yatay düzleme gelen anlık tüm güneş 1şınımının hesaplanabileceği bağıntılar Eşitlik (5) ve (6)'da verilmektedir [23].

$$
\begin{aligned}
& \frac{\mathrm{I}_{\mathrm{a}}}{\mathrm{Q}}=\frac{\pi}{4 \mathrm{t}_{\mathrm{g}}}=\left(\cos \left(\frac{180 \omega}{2 \omega_{\mathrm{s}}}\right)+\frac{2}{\sqrt{\pi}}(1-\psi)\right) \\
& \psi=\exp \left(-4\left(1-\frac{|\omega|}{\omega_{\mathrm{s}}}\right)\right)
\end{aligned}
$$

\subsection{Düșey Yüzeyler İçin Güneş Ișınımı} Bileşenlerinin Hesaplanması (Calculation of Solar Radiation Components for Vertical Surfaces)

Bina yatay ve düşey yüzeyleri üzerine gelen güneş ışınımının tespit edilebilmesi amacıyla literatürde sıklıkla kullanılan sayısal bir yöntem kullanılmıştır. $I_{\text {ed }}, I_{\text {ey }}$ ve $I_{\text {ya }}$ sırasıyla yüzey üzerine gelen direkt, yayılı ve yansıyan güneş 1şınımı olmak üzere eğik bir düzlem üzerine gelen toplam güneş ışınımı şiddeti (I) aşağıdaki eşitlikle hesaplanır [24-26].

$$
I=\underbrace{R_{d} I_{d}}_{\text {Ied }}+\underbrace{I_{y} \frac{1+\cos \beta}{2}}_{\text {Iey }}+\underbrace{I_{a} \rho \frac{1-\cos \beta}{2}}_{\text {Iya }}
$$

\section{GÜNEŞ ISISI KAZANÇ FAKTÖRÜ DEĞERLERINININ HESAPLANMASI (CALCULATION OF SOLAR HEAT GAIN FACTORS)}

Yatay ve düşey yüzeylere ait GIKF değerleri Powell ve Yellot [27] tarafindan önerilen yaklaşım kullanılarak tanımlanabilir. Yatay yüzeyler için saatlik ısı kazanç faktörü değeri olan GIKF $_{\mathrm{y}}$ aşağıdaki eşitlik ile verilmiştir.

$$
\begin{aligned}
& \mathrm{GIKF}_{\mathrm{y}}=\mathrm{I}_{\mathrm{d}}\left(\tau_{\mathrm{d}}+\mathrm{N}_{\mathrm{i}} \alpha_{\mathrm{d}}\right)+\mathrm{I}_{\mathrm{y}}\left(\tau_{\mathrm{y}}+\mathrm{N}_{\mathrm{i}} \alpha_{\mathrm{y}}\right) \\
& \mathrm{I}_{\mathrm{d}}=\mathrm{I}_{\mathrm{a}}-\mathrm{I}_{\mathrm{y}}
\end{aligned}
$$

Burada; $I_{d}$ yatay düzlemde konumlandırılan camlama (pencere) yüzeyi üzerindeki saatlik doğrudan güneş ışınımı, Iy yatay camlama yüzeyi üzerindeki saatlik yayılı ışınım miktarı, $I_{a}$ ise yatay camlama yüzeyi üzerindeki saatlik toplam ışınım miktarıdır. Ni yutulan güneş 1şınımının iç ortama geçme oranı, $\alpha_{d}$ camlamanın doğrudan güneş ışınımını yutma oranı, $\tau_{d}$ camlamanın doğrudan güneş ışınımını geçirme oranı, $\alpha_{\mathrm{y}}$ referans camlamanın yayılı güneş 1şınımını yutma oranı ve $\tau_{\mathrm{y}}$ camlamanın yayılı güneş ışınımını geçirme oranıdır. Düşey yüzeyler için, saatlik $\mathrm{GIKF}_{\mathrm{d}}$ aşağıdaki eşitlikle ifade edilebilir [27].

$\mathrm{GIKF}_{\mathrm{d}}=\mathrm{I}_{\mathrm{ed}}\left(\tau_{\mathrm{d}}+\mathrm{N}_{\mathrm{i}} \alpha_{\mathrm{d}}\right)+\left(\mathrm{I}_{\mathrm{ey}}+\mathrm{I}_{\mathrm{ya}}\right)\left(\tau_{\mathrm{y}}+\mathrm{N}_{\mathrm{i}} \alpha_{\mathrm{y}}\right)(10$

$\mathrm{I}_{\text {ed }}$ düşey camlama yüzeyi üzerindeki saatlik doğrudan güneş 1şınımı ve $\mathrm{I}_{\mathrm{ey}}+\mathrm{I}_{\mathrm{ya}}$ düşey camlama yüzeyi üzerindeki toplam yayılı ve yansıyan 1şınım miktarıdır. Doğrudan güneş ışınımı için geçirme $\left(\tau_{\mathrm{b}}\right)$ ve yutma $\left(\alpha_{b}\right)$ oranları, yüzeye bağlı olarak güneş 1şınımının geliş açısının bir fonksiyonudur [7, 11, 28].

$\tau_{d}=-0,00885+2,71235 \cos \theta-0,62062 \cos ^{2} \theta$

$-7,07329 \cos ^{3} \theta+9,75995 \cos ^{4} \theta$

$-3,89922 \cos ^{5} \theta$

$\alpha_{b}=0,001154+0,77674 \cos \theta$

$-3,94657 \cos ^{2} \theta+8,57881 \cos ^{3} \theta$

$-8,38135 \cos ^{4} \theta+3,01188 \cos ^{5} \theta$

Yatay ve düşey düzlemler için GIKF hesaplamalarında takip edilen akış şemaları Şekil 5'te görülmektedir.

Yayılı bileşenler için Stephenson, $\tau_{\mathrm{d}}$ ve $\alpha_{\mathrm{d}}$ değerlerini sırasıyla 0,799 ve 0,0544 olarak hesaplamıştır [28]. Hesaplamalarda bu değerler kullanılmıştır. Bunun yanı sıra yutulan ışınımın iç ortama geçme oranı $\left(\mathrm{N}_{\mathrm{i}}\right)$ şu şekilde ifade edilebilir.

$\mathrm{N}_{\mathrm{i}}=\mathrm{h}_{\mathrm{i}} /\left(\mathrm{h}_{\mathrm{i}}+\mathrm{h}_{\mathrm{o}}\right)=\underbrace{8,29}_{\text {hi }} / 8,29+\underbrace{16,21 \mathrm{~V}_{\mathrm{s}}^{0,452}}_{\text {ho }}]$

Burada $h_{i}$ ve $h_{o}$ sırasıyla iç ve dış ortam 1sı taşınım katsayılarıdır. İç ortamda doğal taşınım olduğu varsayıldığından genel bina tasarımı için önerilen iç ortam taşınım katsayısı $\mathrm{h}_{\mathrm{i}}=8,29 \mathrm{~W} / \mathrm{m}^{2} \mathrm{~K}$ olarak alınmıştır [9]. $h_{o}$ 'a ait daha doğru sonuçlar elde edebilmek için Loveday ve Taki [29] tarafindan yakın yüzey rüzgar hızına $\left(\mathrm{V}_{\mathrm{s}}\right)$ bağlı olarak öne sürülen Eşitlik (13)'teki matematiksel ifade kullanılmıştır.

Yatay yüzeyler için ölçülen rüzgar hızı $\left(\mathrm{V}_{\mathrm{r}}\right)$ yakın yüzey rüzgar hızına $\left(\mathrm{V}_{\mathrm{s}}\right)$ eşit kabul edilir. Düşey yüzeyler için ise bina yüzeyine önden gelen rüzgarın geliş açısının $20^{\circ}-160^{\circ}$ olması durumunda Eşitlik (14) rüzgar geliş açısının diğer yönlerde olması durumunda Eşitlik (15) kullanılır.

$V_{s}=0,68 V_{r}-0,5$

$V_{S}=0,157 V_{r}-0,027$ 


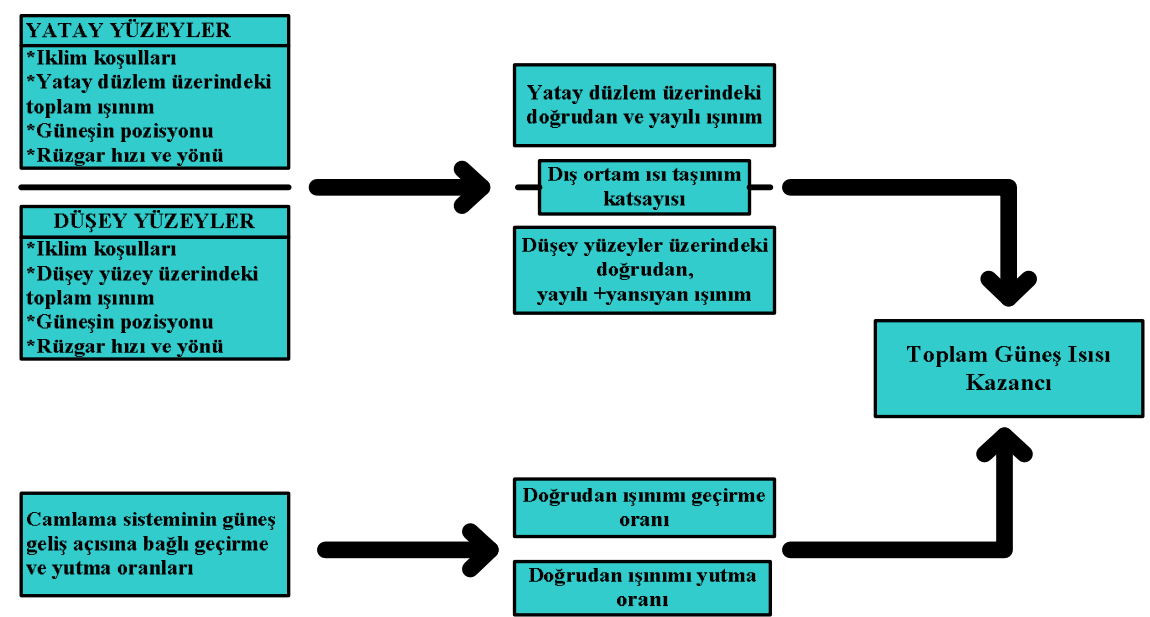

Şekil 5. Yatay ve düşey yüzeyler için GIKF hesaplamalarında kullanılan iş akış şeması (Flow chart of GIKF employed calculations of horizontal and vertical surfaces)

\section{BULGULAR VE DEĞERLENDİRME (FINDINGS AND EVALUATION)}

Uygulama çalışması Elazığ iline ait 27 Temmuz 2010 - 4 Temmuz 2011 iklimsel verileri ile 343 günlük bir zaman periyodu $(343 \times 24=8232$ saat $)$ için gerçekleştirilmiştir. Bu döneme ait Elazığ iline ait dış ortam sıcaklığı, günlük güneşlenme süresi ve saatlik rüzgar hızı ve yönü iklimsel verileri Devlet Meteoroloji İşleri Genel Müdürlüğü'nden temin edilmiştir. GIKF değerleri iç ortam sıcaklığının $19^{\circ} \mathrm{C}$ sabit olduğu durum için hesaplanmıştır. Çalışmada yatay düzlem ve dört adet düşey yüzeye ait toplam güneş 1şınımı değerleri Furat Üniversitesi yerleşkesine inşa edilen bir bina prototipi üzerinden ölçülmüştür. Bina prototipi zemine güney $\left(\gamma=0^{\circ}\right)$, kuzey $\left(\gamma= \pm 180^{\circ}\right)$, doğu $\left(\gamma=-90^{\circ}\right)$, batı $\left(\gamma=90^{\circ}\right)$ azimut açıları ile oturtulmuştur. $\mathrm{Bu}$ varsayım ve kabuller işığında aşağıdaki bulgular elde edilmiştir.

Şekil 6'da görüldüğü üzere Temmuz ve Ağustos aylarında yatay düzlemler bina düşey yüzeylerine gelen güneş 1şınımından daha yüksek ışınım ve GIKF değerlerine sahiptirler. Son yıllarda çok katlı ve giydirme cam cepheli binaların artması ile bina dış yüzey alanı ile karşılaştırıldığında, çatı yüzeyleri oldukça küçük kalmaktadır. Buradan bina 1sıl yükleri üzerinde asıl belirleyici olan yüzeylerin bina düşey yüzeyleri olduğu anlaşılmaktadır. Özellikle yaz aylarında sabah saatlerinde doğu, öğleden sonra ise batı cephelerde yaklaşık $600 \mathrm{~W} / \mathrm{m}^{2}$ civarındaki GIKF değerleri binalarda soğutma gereksinimini doğrudan etkilemektedir. Bu aylar için saatlik maksimum GIKF değerleri sıralandığında yatay düzlemleri sırasıyla doğu, batı, güney ve kuzey yönleri takip etmektedir. Eylül ayının gelmesi ile birlikte güney cephelere ait GIKF değeri en yüksek $575 \mathrm{~W} / \mathrm{m}^{2}$ seviyelerine ulaşmaktadır. Yatay düzleme ait GIKF $733 \mathrm{~W} / \mathrm{m}^{2}$ ile halen gün içerisindeki en yüksek değere sahip iken, kuzey cephe $202 \mathrm{~W} / \mathrm{m}^{2}$ seviyelerindedir. Doğu cephelerde bir önceki aya göre $\% 3,3$ artış varken, batı yönünde \% 27,4'lük bir düşüş gözlemlenmiş̧ir. Ekim ayı için verilen grafik dikkate alındığında yatay düzlem ve güney yönüne ait GIKF'lerin yakın değerler almaya başladığı görülmektedir. Ancak halen doğu cepheler güneş 1sısı kazancında sabah saatlerinde $565 \mathrm{~W} / \mathrm{m}^{2}$ gibi önemli seviyelerdedir. Ölçüm yapılan bölgenin batısında yer alan coğrafi engeller nedeniyle zaten eğik gelen güneş ışınımı batı cepheler üzerinde tesirli olamamaktadır. Bu nedenle bu ay için ölçülen en yüksek saatlik ortalama değer bu yön için $177 \mathrm{~W} / \mathrm{m}^{2}$ seviyesinde kalmıştır. Kasım ayıyla birlikte 1sıtma periyoduna girilmesi ile güneş 1sısı kazancında maksimum fayda sağlayan cephe güney olmaktadır. Güney cephe yıl boyunca aldığ 1 en yüksek GIKF değeri olan $703 \mathrm{~W} / \mathrm{m}^{2}$ ye ulaşmıştır. Yaz aylarında yoğun güneș işınımına maruz kalmadığından bina soğutma yükleri üzerinde belirgin bir etkisi olmayan güney cephe açıklıkları, kış aylarında sağladıkları faydalı kazanç ile ısıtma enerjisi ihtiyacını önemli ölçüde azaltmaktadır. Aralık ayında doğu cephe güneş 1şınımı kazancındaki etkinliğini kaybetmiştir. Uzun yılların ortalamalarında daha yüksek değerler almış olmasına rağmen 2010 y1lı Aralık ayında güneşlenme sürelerindeki düşme nedeniyle grafikten de anlaşılacağı üzere özellikle güney cephede oldukça düşük GIKF değerleri elde edilmiştir. Bu ay için bütün yönler dikkate alındığında en yüksek kazançların güney cepheler ile yatay düzlemlerde elde edildiği açıkça görülmektedir. Ocak ayında elde edilen güneş 1sısı kazançlarına bakıldığında güney yönünden sonra en yüksek değerlerin doğu yönünde elde edildiği görülmüştür. Ancak Şubat ayı ile birlikte güney yönünü sırasıyla yatay, doğu, batı ve kuzey yönleri izlemektedir. Ocak ayında karşılaşılan bu durumu değerlendirirken (Şekil 7) sadece o yıla ait gölgeleme, yăğş̧ durumu, güneşlenme süresi vb. farklı iklimsel değişkenlerden kaynaklanabileceği göz önünde bulundurulmalıdır. Kış mevsiminin mevsim normallerinden daha sıcak geçtiği 2010-2011 yıllarında yürütülen bu çalışmanın sonuçlarından yola çıkılarak bu aylar için bir genelleme yapılması hatalı sonuçlara sebebiyet verebilir. 

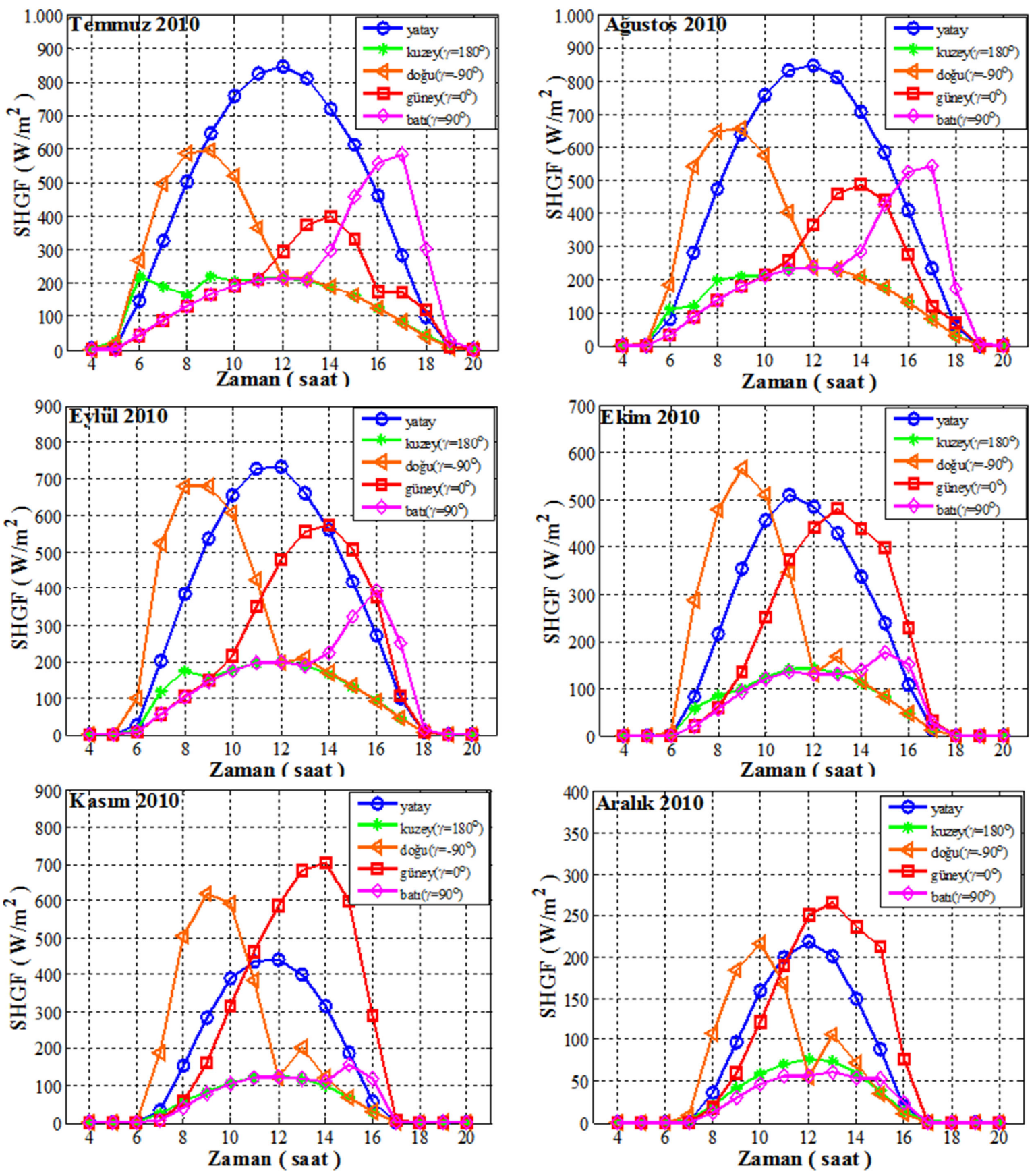

Şekil 6. 2010 yılı ikinci altı ayı için hesaplanan aylık ortalama saatlik GIKF değerleri (Average hourly GIKF's calculated for the $2^{\text {nd }}$ half of 2010)

Mart ayının gelmesi ile birlikte de güney cepheler güneş 1S1S1 kazancındaki etkinliğini kaybetmiştir. Günlük maksimum değerinde bir önceki aya göre \% 33,15 artış olan doğu cepheler yatay düzlemden sonra yüksek GIKF değerine sahip olan yön olmuştur. Bu iki yönü takiben en yüksek GIKF değerlerinin sırasıyla güney, kuzey ve batı yönlerine ait olduğu tespit edilmiştir. Kış dönemi boyunca ölçüm yapılan yerin yakın çevresindeki topoğrafya nedeniyle batı cephe üzerine düşen güneş ışınımı normalin altında değerler almıştır. Şekil 7'de görüldüğü üzere Nisan ayıyla birlikte güneş ışınlarının yerküreye daha dik gelmesi, batı cephe üzerine gelen güneş ışınımını engelleyen topoğrafik unsurların olumsuz etkilerini ortadan kaldırmıştır. Nisan ayında günlük maksimum GIKF değeri Mart ayına göre \% 6,1 oranında artarak yine en yüksek değere sahip olan yatay düzlemi, sırasıyla doğu, güney, batı ve kuzey yönleri takip etmektedir. Bir önceki aya göre $\% 40,8$ oranında daha düşük GIKF'ye sahip olan güney cepheler bu aydan itibaren güneş 1S1s1 kazancındaki etkinliğini kaybetmektedir. Şekil 7'de soğutma periyodunda yatay düzlemin diğer yönlere göre çok daha yüksek GIKF değerine sahip olduğu görülmektedir. Mayıs ve Haziran aylarında bina soğutma ihtiyaçlarını doğrudan belirleyen batı ve doğu cephelere ait güneş 
1Sısı kazancı değerlerinin yatay düzlemden hemen sonra en etkili yönler olduğu görülmüştür. Güney cepheler ise bu dönemde güneş ışınlarının yeryüzüne daha dik bir açı ile gelmesiyle kuzey yönüne çok yakın GIKF'ye sahip olmaktadır.

5.1 Hesaplanan GIKF ile ASHRAE Tablo Değerlerinin Karşılaştırılması (Comparison of the calculated GIKF with ASHRAE's table values )

ASHRAE, $0^{\circ}$ den $64^{\circ}$ kuzey enlemine kadar her $8^{\circ}$ enlem dairesi için sayısal olarak türetilmiş GIKF değerlerini tablolar halinde vermektedir. Çalışmanın bu aşamasında $38,4^{\circ}$ kuzey enleminde yer alan Elazı ğ
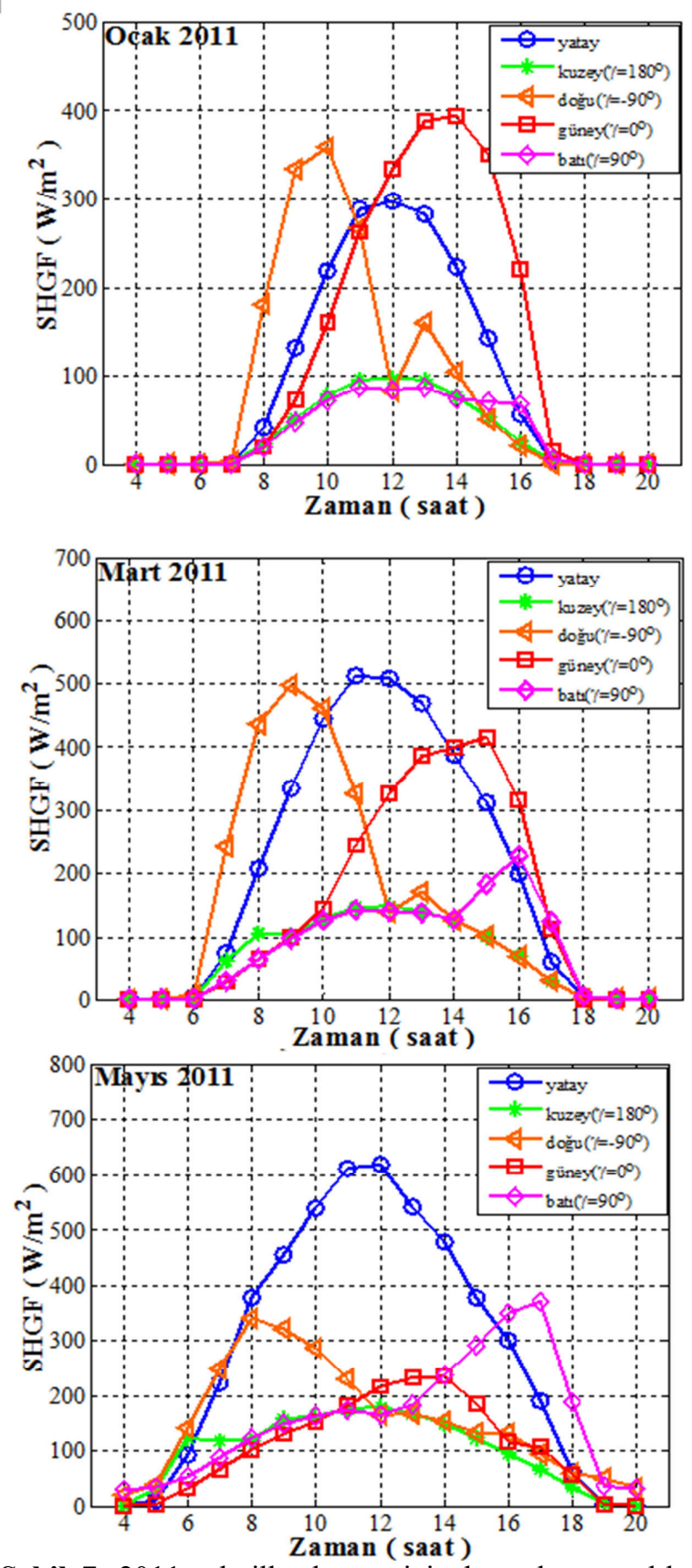

Şekil 7. 2011 yılı ilk altı ayı için hesaplanan aylık ortalama saatlik GIKF değerleri (Average hourly GIKF's calculated for the $1^{\text {st }}$ half of 2011) ili için ölçülen ve hesaplanana güneş ışınımı verileri kullanılarak elde edilen GIKF değerleri ASHRAE'nin $40^{\circ}$ kuzey enlemi için vermiş olduğu değerler ile mukayese edilmiştir. Yatay düzleme ait aylık ortalama günlük toplam GIKF değerleri ASHRAE tarafından açık gökyüzü koşulları için verilen değerler ile karşılaştırılmıştır. Temmuz 2010 ve Şubat 2011 dönemi arasında hesaplanan ve ASHRAE tarafindan verilen değerlerin birbirine yakın olduğu görülmektedir. Ancak özellikle Şubat-Temmuz 2011 dönemi arasında ASHRAE tarafindan $40^{\circ}$ kuzey enlemi için verilen değerler $38,4^{\circ}$ kuzey enleminde yer alan Elazı̆̆ için hesaplanan değerlerden çok yüksektir. Öyle ki, bu fark aylara göre değişmekle
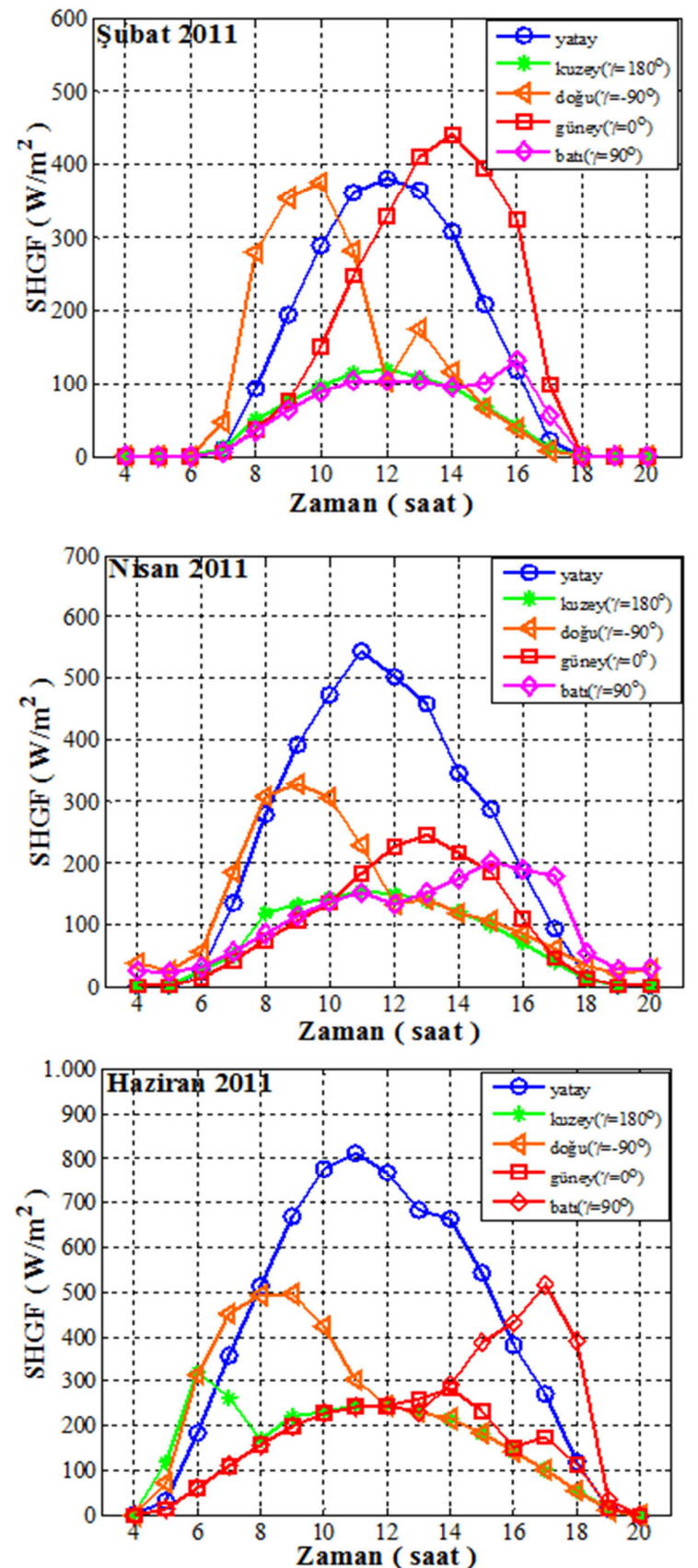

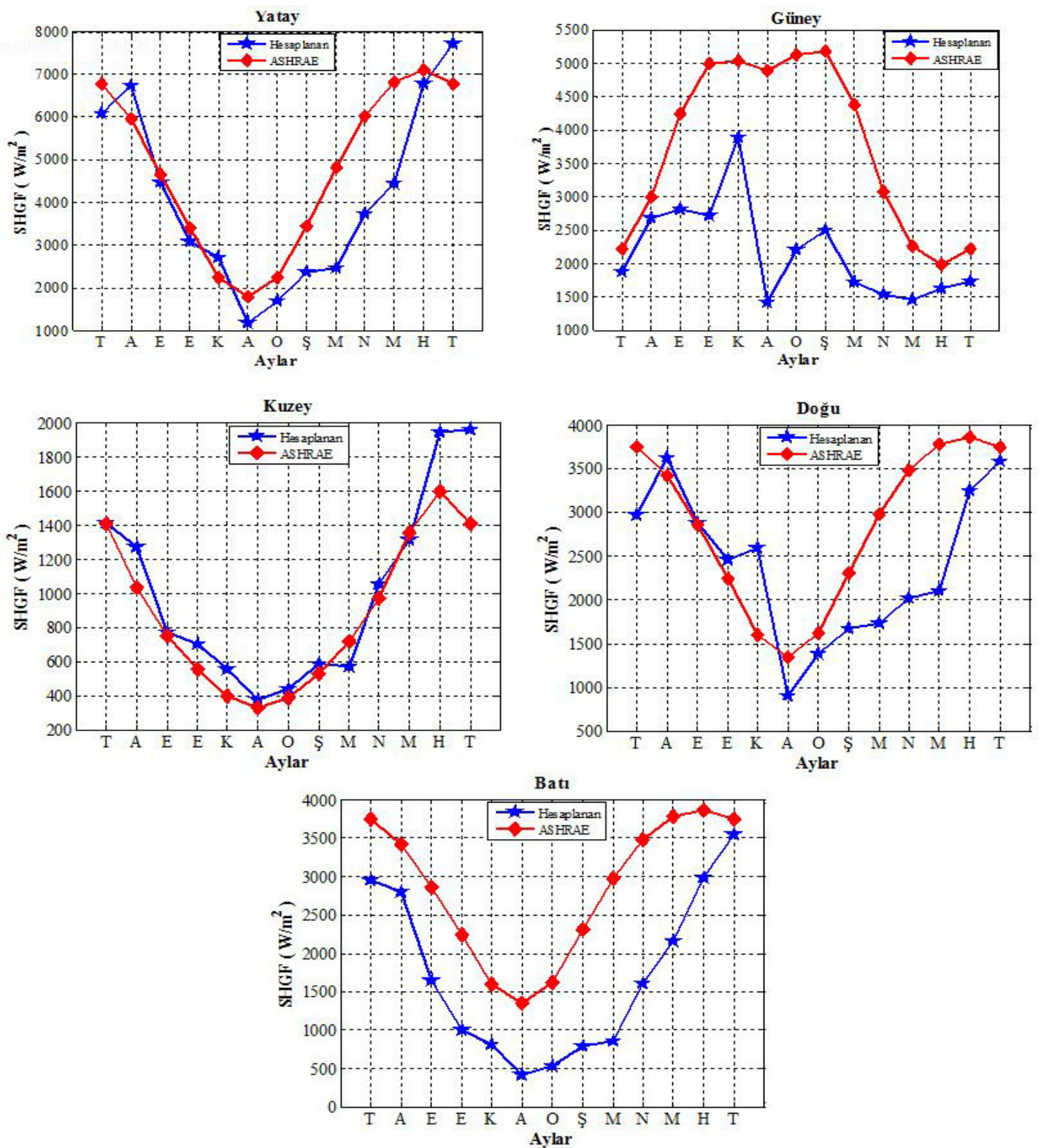

Şekil 8. Farklı yüzeyler için hesaplanan GIKF’lerin ASHRAE tablo değerleri ile karşılaştırılması (Comparison of the calculated GIKF's with ASHRAE's table values for different surfaces)

birlikte $325 \mathrm{~W} / \mathrm{m}^{2}$ ile $2298 \mathrm{~W} / \mathrm{m}^{2}$ arasında değerler almaktadır. Güney cepheler için elde edilen GIKF değerlerinin ASHRAE tarafindan verilen değerlerden oldukça düşük olduğu Şekil 8 'de açıkça görülmektedir. Devlet Meteoroloji İșleri Genel Müdürlüğü’nden alınan günlük güneşlenme süreleri ile hesaplanan güneş, 1şınımı değerleri de bu sonucu doğrulamaktadır. Temmuz - Ağustos - Eylül 2010 dönemi ile Mayıs - Haziran - Temmuz 2011 dönemlerine ait GIKF değerleri birbirine yakın sonuçlar vermiştir. Buna rağmen isıtma periyodu için elde edilen sonuçların bazı aylar için $145 \mathrm{~W} / \mathrm{m}^{2}$ ile $3455 \mathrm{~W} / \mathrm{m}^{2}$ arasında değişen miktarda farklı olduğu durumlar ortaya çıkmıştır. Kuzey cepheler için hesaplanan ve ASHRAE tarafindan verilen GIKF'ler değerlendirildiğinde özellikle 2011 yılının ilk altı ayı için birbirine çok yakın sonuçlar elde edilmiştir. 2010 yılının ikinci yarısı için ise günlük toplamda 117
$\mathrm{W} / \mathrm{m}^{2}$ ile $590 \mathrm{~W} / \mathrm{m}^{2}$ lik farkların olduğu durumlara rastlanmıştır. Ancak yaz (özellikle Temmuz- AğustosEylül 2010 ve Haziran-Temmuz 2011) döneminde grafikte görülen aşırı farkların, ölçüm düzeneği yakın çevresinde konumlandırılmış, olan binaların camlı yüzeylerinden olan yansımalardan kaynaklandığı düşünülmektedir. Doğu yönü Temmuz-Kasım 2010 dönemi için hesaplanan GIKF değerlerinin ASHRAE tarafindan verilen değerlerden $129 \mathrm{~W} / \mathrm{m}^{2}$ ile 1233 $\mathrm{W} / \mathrm{m}^{2}$ arasında değişen miktarlarda daha yüksek değerler aldığı görülmüștür. Aralık 2010 - Temmuz 2011 döneminde ise hesaplanan değerlerin ASHRAE tarafindan verilen değerlerden $52 \mathrm{~W} / \mathrm{m}^{2}$ ile 1164 $\mathrm{W} / \mathrm{m}^{2}$ arasında değişen miktarlarda daha düşük değer aldığı görülmüş̧ür. Batı yönündeki güneş, ışınımı ölçümlerinin ölçüm yapılan bina prototipinin batısında yer alan topoğrafik engellerden dolayı 1sıtma periyodunda normalin altında ölçüldüğü ifade 
edilmişti. Şekilden de görüldüğü üzere yaz aylarında ASHRAE değerlerine yakın değerler elde edilmesine rağmen kış döneminde aylara göre $619 \mathrm{~W} / \mathrm{m}^{2}$ ile 1710 $\mathrm{W} / \mathrm{m}^{2}$ arasında değişen farklara rastlanmıştır.

\section{SONUÇLAR (CONCLUSIONS)}

Elazı̆̆ iline ait GIKF değerlerinin belirlenebilmesi amacıyla Fırat Üniversitesi yerleşkesi içerisinde bir bina prototipinin yatay ve düşey yüzeyleri üzerinden güneş 1şınımı ölçümleri yapılmıştır. Ölçülen güneş ışınımı ve Devlet Meteoroloji İşleri Genel Müdürlüğü'nden temin edilen iklimsel verilerle aylık ortalama saatlik GIKF değerleri hesaplanmıştır. Sonuçlardan yola çıkarak yatay yüzeyler yıl boyunca yoğun güneş 1şınımına maruz kaldığından bu yüzeylerde gerekli olmadıkça çatı aydınlatması kullanılmaması, çok gerekli olduğu durumlarda ise gölgeleme ekipmanı ile kullanımı ve günün belirli saatlerinde kapatılması önerilmektedir. Pencerelerden güneş 1Sısı kazancının kış aylarında maksimum yaz aylarında minimum seviyede tutulması için cephelerdeki saydam yüzeylerin mümkün oldukça güney yönünde konumlandırılması faydalı olacaktır. Doğu ve batı yönleri gibi yazın aşırı 1sınmalara sebebiyet veren kışında düşük güneş 1Sıs1 kazanc1 sağlayan cephelerde konumlandırılacak olan pencerelerin sinırlı tutulması da binaların enerji etkin olarak tasarlanmasında etkili olacaktır.

ASHRAE'nin $40^{\circ}$ kuzey enlemi için verdiği GIKF değerlerinin bazı durumlarda Elazığ ili için hesaplanan değerlerden neredeyse \% 90 daha yüksek sonuçlar verdiği gözlenmiştir. Farklılıkların sebebi ölçüm yapılan dönemin yaklaşık bir sene ile sınırlandırılmış olması ve bu dönemde mevsim normalleri dişında seyreden sicaklık ve yağış durumu olabilir. Bu konuda kesin yargıya varılması için çalışmanın uzun yıllar için yapılacak güneş 1şınımı, sıcaklık ve rüzgar hızı ve yönü ölçümleri ile desteklenmesi ve bölge hakim iklim koşullarının doğru olarak tespit edilmesi gerektirmektedir. Ancak yine de açık gökyüzü varsayımı ile $40^{\circ}$ kuzey enlemi için yapılan hesaplamaların sonuçlarına dayanan ve uzun zamandır güncellenmemiş olan bu tablo verilerinin kullanılmasının ülkemiz için gerçekçi uygulamalara firsat vermeyeceği açıtır.

\section{TEŞEKKÜR (ACKNOWLEDGEMENTS)}

Fırat Üniversitesi Bilimsel Araştırma Projeleri (FÜBAP) birimine çalışmamıza verdikleri maddi destekten dolayı teşekkür ederiz.

\section{SEMBOLLER (SYMBOLS)}

$\mathbf{h}_{\mathbf{i}}: \quad$ iç ortam 1 șı taşınım katsayısı $\left(\mathrm{W} / \mathrm{m}^{2} \mathrm{~K}\right)$

$\mathbf{h}_{\mathbf{0}}$ : diş ortam 1 șı taşınım katsayısı $\left(\mathrm{W} / \mathrm{m}^{2} \mathrm{~K}\right)$

I: eğik düzlem üzerindeki toplam güneş 1 şınımı $\left(\mathrm{W} / \mathrm{m}^{2}\right)$
$\mathbf{I}_{\mathbf{a}}$ : yatay düzlem üzerindeki anlık tüm güneş 1şınımı $\left(\mathrm{W} / \mathrm{m}^{2}\right)$

$\mathbf{I}_{\text {ed }}$ : eğik düzleme gelen doğrudan güneş 1şınımı $\left(\mathrm{W} / \mathrm{m}^{2}\right)$

$\mathbf{I}_{\text {ey }}$ : eğik düzleme gelen yayılı güneş 1şınımı $\left(\mathrm{W} / \mathrm{m}^{2}\right)$

$\mathbf{I}_{\mathbf{y}}$ : $\quad$ yatay düzlem üzerindeki yayılı güneş 1 şınımı $\left(\mathrm{W} / \mathrm{m}^{2}\right)$

$\mathbf{I}_{\text {ya }}$ : eğik düzleme yansıyarak gelen güneş 1 şınımı $\left(\mathrm{W} / \mathrm{m}^{2}\right)$

$\mathbf{K}_{\mathbf{t}}: \quad$ berraklık indeksi (boyutsuz)

$\mathbf{K}_{\mathbf{y}}$ : yatay düzleme gelen yayılı ışınımın tüm güneş 1şınımına oranı (boyutsuz)

Q : yatay birim düzleme gelen toplam güneş 1Şınımı $\left(\mathrm{W} / \mathrm{m}^{2}\right)$

$\mathbf{Q}_{\mathbf{0}}$ : atmosfer dışındaki yatay birim düzleme bir gün boyunca gelen toplam güneş 1şınımı ( $\mathrm{MJ} / \mathrm{m}^{2}$ gün)

$\mathbf{N}_{\mathbf{i}}$ : yutulan 1şınımın iç ortama geçme oranı

$\mathbf{R}_{\mathbf{d}}$ : yatay düzleme doğrudan gelen güneş ışınımının eğik düzleme doğrudan gelen güneş ışınımına oranı (boyutsuz)

T : günlük güneşlenme süresi (saat)

$\mathbf{t}_{\mathrm{g}}:$ gün uzunluğu (saat)

$\mathbf{V}_{\mathbf{r}}:$ rüzgar hızı $(\mathrm{m} / \mathrm{s})$

$\mathbf{V}_{\mathrm{s}}$ : yakın yüzey rüzgar hızı $(\mathrm{m} / \mathrm{s})$

$\alpha_{d}$ : camlamanın doğrudan güneş 1şınımını yutma oranı (boyutsuz)

$\alpha_{\mathrm{y}}$ : camlamanın yayılı güneş ışınımını yutma oranı (boyutsuz)

$\beta$ : $\quad$ yüzey eğim açısı $\left({ }^{\circ}\right)$

$\delta: \quad$ deklinasyon açısı $\left(^{\circ}\right)$

$\theta: \quad$ güneş geliş açısı $\left({ }^{\circ}\right)$

$\rho: \quad$ yerin yansitma oranı (boyutsuz)

$\tau_{\mathrm{d}}$ : camlamanın doğrudan güneş ışınımını geçirme oranı (boyutsuz)

$\tau_{\mathrm{y}}$ : camlamanın yayılı güneş 1şınımını geçirme oranı (boyutsuz)

$\phi: \quad$ enlem açısı $\left(^{\circ}\right)$

$\omega: \quad$ saat açısı $\left(^{\circ}\right)$

$\omega_{\mathrm{s}}$ : güneş doğuş/batış saat açısı $\left(^{\circ}\right)$

\section{KAYNAKLAR (REFERENCES)}

1. Ekici, B.B., Gülten, A.A. ve Aksoy, U.T., "A Study on the Optimum Insulation Thicknesses of Various Types of External Walls with Respect to Different Materials Fuels and Climate Zones in Turkey", Applied Energy, Cilt 92, 211-217, 2012.

2. Aytaç, A. ve Aksoy, U.T., "The Relation Between Optimum Insulation Thickness and Heating Cost on External Walls for Energy Saving", Journal of the Faculty of Engineering and Architecture of Gazi University, Cilt 21, No 4, 753-758, 2006.

3. Aksoy, U.T. ve Keleşoğlu, Ö., "Effects of Building Envelope Surface Area and Insulation Thickness on Heating Cost", Journal of the Faculty of Engineering and Architecture of Gazi University, Cilt 22, No 1, 103-109, 2007. 
4. Oral, G.K. ve Yilmaz, Z., "The Limit U Values for Building Envelope Related to Building Form in Temperate and Cold Climate Zones", Building and Environment, Cilt 37, 1173-1180, 2002.

5. Ekici, B.B., Binalarda Güneş Isısı Kazanç Faktörü ve Yüzey Sıcaklıklarının Saydam ve Opak Yüzey Tasarımına Etkisinin Deneysel Olarak Araştırılması, Doktora Tezi, Fırat Üniversitesi, Fen Bilimleri Enstitüsü, 2012.

6. ASHRAE, ASHRAE Handbook 1997 Fundamentals, American Society of Heating, Refrigerating and Air-Conditioning Engineers, Atlanta, GA., 1997.

7. Li, D.H.W. ve Lam, J.C., "Solar Heat Gain Factors and the Implications to Building Designs in Subtropical Regions", Energy and Buildings, Cilt 32, 47-55, 2000.

8. Marinoski, D.L., Guths, S., Pereira, F.O.R. ve Lamberts, R., "Improvement of a Measurement System for Solar Heat Gain Through Fenestrations", Energy and Buildings, Cilt 39, 478-487, 2007.

9. Li, D.H.W. ve Lam, J.C., "Analysis of Solar Heat Gain Factors Using Sky Clearness Index and Energy Implications", Energy Conversion and Management, Cilt 42, 555-571, 2001.

10. Bhandari, M.S. ve Bansal, N.K., "Solar Heat Gain Factors and Heat Loss Coefficients for Passive Heating Concepts", Solar Energy, Cilt 53, 199208, 1994.

11. Li, D.H.W. ve Lam, J.C., "Development of Solar Heat Gain Factors Database Using Meteorological Data", Building and Environment, Cilt 36, 469-483, 2001.

12. Hernandez, M., Medina, M.A. ve Schruben, D.L., "Verification of an Energy Balance Approach to Estimate Indoor Wall Heat Fluxes Using Transfer Functions and Simplified Solar Heat Gain Calculations", Mathematical and Computer Modelling, Cilt 37, 235-243, 2003.

13. Hamdy, I.F. ve Fikry, M.A., "Passive Solar Ventilation", Renewable Energy, Cilt 14, 381386, 1998.

14. Levinson, R., Akbari, H. ve Berdahl, P., "Measuring Solar Reflectance-Part I: Defining a Metric that Accurately Predicts Solar Heat Gain", Solar Energy, Cilt 84, 1717-1744, 2010.

15. Pereira, F.O.R. ve Sharples, S., "The Development of a Device for Measuring Solar Heat Gain and Shading Coefficients of Windows in Scale Models", Energy and Buildings, Cilt 17, 271281, 1991.

16. Pal, S., Roy, B. ve Neogi, S., "Heat Transfer Modelling on Windows and Glazing Under the Exposure of Solar Radiation", Energy and Buildings, Cilt 41, 654-661, 2009.
17.Li, D.H.W., Lam, T.N.T., Wong, S.L. ve Tsang, E.K.W., "Lighting and Cooling Energy Consumption in an Open-plan Office Using Solar Film Coating", Energy, Cilt 33, 1288-1297, 2008.

18. Kumar, R. ve Umanand L., "Estimation of Global Radiation Using Clearness Index Model for Sizing Photovoltaic System", Renewable Energy, Cilt 30, 2221-2233, 2005.

19. Poudyal, K.N., Bhattarai B.K., Sapkota, B. ve Kjeldstad B., "Estimation of Global Solar Radiation Using Clearness Index and Cloud Transmittance Factor a Trans-Himalayan Region in Nepal", Energy and Power Engineering, Cilt 4, 415-421, 2012.

20.Erbs, D.G., Klein, S.A. ve Duffie, J.A., "Estimation of the Diffuse Fraction for Hourly Daily and Monthly-average Global Radiation", Solar Energy, Cilt 28, No 4, 293-302, 1982.

21. Prescott J.A., "Evaporation from a water surface in relation to solar radiation", Transactions and Proceedings of the Royal Society of South Australia, Cilt 64, 114-148, 1940.

22. Klein, S.A., "Calculation of monthly average insolation on tilted surfaces", Solar Energy, Cilt 21, 393-402, 1977.

23. Aksoy U.T., İklimsel Konfor Açısından Bina Yönlendirilmesi ve Bina Biçimlendirmesinin Isıtma Maliyetine Etkisi, Doktora Tezi, Firat Üniversitesi Fen Bilimleri Enstitüsü, 2002.

24. Mediavilla, M.D., Miguel, A.D. ve Bilbao, J., "Measurement and Comparison of Diffuse Solar Irradiance Models on Inclined Surfaces in Valladolid (Spain)", Energy Conversion and Management, Cilt 46, 2075-2092, 2005.

25. Gueymard, C., "Predicting and Performance Assessment of Mean Hourly Global Solar Radiation", Solar Energy, Cilt 68, 285-303, 2000.

26. Li, D.H.W., Lam, J.C. ve Lau, C.C.S., "A New Approach for Predicting Vertical Global Solar Irradiance", Renewable Energy, Cilt 25, 591606, 2002.

27. Powell, G.L. ve Yellott, J.I., "Solar Heat Gain Factors on Average Days", Proceedings of the American Section of the International Solar Energy Society Annual Meeting, Phoenix, AZ, 826-830, 1980.

28. Stephenson, D.G., "Equations for Solar Heat Gain Through Windows", Solar Energy, Cilt 9, 81-86, 1965.

29. Loveday D.L. ve Taki, A.H., "Convective Heat Transfer Coefficients at a Plane Surface on a Full-scale Building Facade", International Journal of Heat and Mass Transfer, 39, 17291742, 1996. 
